\title{
Safety and long-term efficacy of ventro-oral thalamotomy for focal hand dystonia
}

\section{A retrospective study of 171 patients}

Shiro Horisawa, MD, Taku Ochiai, PhD, Shinichi Goto, MD, Takeshi Nakajima, PhD, Nobuhiko Takeda, MD, Atsushi Fukui, MD, Tomoko Hanada, MD, Takakazu Kawamata, PhD, and Takaomi Taira, PhD

Neurology ${ }^{\circledR}$ 2019;92:e371-e377. doi:10.1212/WNL.0000000000006818

\section{Abstract}

\section{Objective}

To report the safety and long-term efficacy of ventro-oral thalamotomy for 171 consecutive patients with task-specific focal hand dystonia.

\section{Methods}

Between October 2003 and February 2017, 171 consecutive patients with task-specific focal hand dystonia underwent unilateral ventro-oral thalamotomy. Etiologies included writer's cramps $(\mathrm{n}=92)$, musician's dystonias $(\mathrm{n}=58)$, and other occupational task-related dystonias $(n=21)$. The task-specific focal hand dystonia scale was used to evaluate patients' neurologic conditions (range 1-5, high score indicated a better condition). The scores before surgery; at 1 week, 3 months, and 12 months postoperatively; and the last available follow-up period were determined. Postoperative complications and postoperative recurrence were also evaluated.

\section{Results}

The scores before surgery; at 1 week $(1.72 \pm 0.57,4.33 \pm 0.85[p<0.001]), 3$ months $(4.30 \pm$ $1.06[p<0.001])$, and 12 months $(4.30 \pm 1.13[p<0.001])$; and the last available follow-up $(4.39 \pm 1.07[p<0.001])$ postoperatively improved. The mean clinical follow-up period was $25.4 \pm 32.1$ months (range: $3-165$ ). Permanent adverse events developed in 6 patients (3.5\%). Eighteen patients developed recurrent dystonic symptoms postoperatively. Of these 18 patients, 9 underwent ventro-oral thalamotomy again, of which 7 achieved improvement.

\section{Conclusion}

Ventro-oral thalamotomy is a feasible and reasonable treatment for patients with refractory task-specific focal hand dystonias. Prospective, randomized, and blinded studies are warranted to clarify more accurate assessment of the safety and efficacy of ventro-oral thalamotomy for task-specific focal hand dystonia.

\section{Classification of evidence}

This study provides Class IV evidence that for patients with task-specific focal hand dystonia, ventro-oral thalamotomy improves dystonia.

\author{
Correspondence \\ Dr. Taira \\ ttaira@nij.twmu.ac.jp
}

\section{MORE ONLINE}

$\rightarrow$ Class of Evidence

Criteria for rating

therapeutic and diagnostic

studies

NPub.org/coe

\section{- CME Course}

NPub.org/cmelist 


\section{Glossary}

BTX = botulinum toxin; DBS = deep brain stimulation; TSFD = task-specific focal hand dystonia; vo = ventro-oral.

Dystonia is a movement disorder characterized by involuntary, sustained, and patterned muscle contractions, which cause twisting and repetitive movements. ${ }^{1}$ Focal dystonia manifests in only one part of the body. Most focal hand dystonias frequently present while performing specific tasks and are thus labeled as task-specific focal hand dystonias (TSFDs). ${ }^{2}$ Writer's cramp is the most well-known type of TSFD. ${ }^{3}$ TSFD usually appears after years of repetitive and fine movements associated with specific tasks and are seen in musicians, hairdressers, watchmakers, golfers, table tennis players, marksmen, and jugglers. ${ }^{4-9}$ TSFD can severely interfere with patients' daily lives, and occupational TSFD can be a risk factor for unemployment if not successfully treated. ${ }^{2,10}$

At the current time, available treatments for TSFD are largely unsatisfactory. Botulinum toxin (BTX) injections, trihexyphenidyl, and physical therapy have been used to treat TSFD. ${ }^{11-13}$ Of these, BTX injections into affected muscles are the most widely used treatment option. ${ }^{11}$ However, in case of musicians with TSFD (musician's dystonia), more than half of these musicians ultimately end their musical careers despite these available treatments. ${ }^{10}$ Those for whom BTX treatments fail often seek other treatment options.

Although several studies have demonstrated the high efficacy of lesioning on ventro-oral (vo) nucleus of the thalamus (vothalamotomy) for TSFDs, these are limited to case reports and a few small-scale studies. ${ }^{7,9,14-23}$ We herein retrospectively report on the safety and long-term efficacy of vo-thalamotomy in 171 consecutive patients with TSFD. This is the largest case series involving follow-up study of patients who undergo vothalamotomy for TSFD.

\section{Methods}

\section{Patient population}

Between October 2003 and February 2017, 219 consecutive patients with writer's cramp and other occupational dystonias underwent unilateral vo-thalamotomy by a single surgeon (T.T.) at a single center (Tokyo Women's Medical University Hospital). The inclusion criteria included a minimum of 1-year postsymptom onset and a previous diagnosis of TSFD by other neurologists. The exclusion criteria were cognitive dysfunction; distribution of dystonic symptoms over multiple regions; neurologic conditions such as neurodegenerative disorders, stroke, or cerebral palsy. In total, 171 patients were enrolled in this study. Of these, 48 patients were excluded based on the following criteria: multiple dystonia regions (36) and other neurologic conditions (12).

\section{Standard protocol approvals, registrations, and patient consents}

The data for this study were retrospectively collected and analyzed. The ethics committee of our institution approved this study, and considering the observational nature of the study, patient consent was waived.

\section{Surgical procedures}

Under local anesthesia, a Leksell stereotactic frame (Elekta, Stockholm, Sweden) was fixed onto the skull of the patient. T1-weighted axial and T2-weighted coronal MRI (1-mm slice) and CT scans (1-mm slice) were used to determine the tentative target $2 \mathrm{~mm}$ posterior to the midpoint of the anterior commissure-posterior commissure line, $1 \mathrm{~mm}$ dorsal to the anterior commissure-posterior commissure line, and 13.5 to $15 \mathrm{~mm}$ lateral of midline. This point corresponds to the junction between the ventro-oral anterior and posterior of the thalamus according to the stereotactic atlas of Schaltenbrand and Wahren. ${ }^{24}$ The operation was performed under local anesthesia without sedation. A Leksell neurogenerator (Elekta) was used for stimulation and coagulation. During the surgery, the patient performed affected tasks and was asked to report symptom fluctuations (figure 1A). A monopolar radiofrequency probe $(1.0-\mathrm{mm}$ diameter tip with a $4.0-\mathrm{mm}$ uninsulated length) was inserted through a frontal burr hole. Electrical stimulation $(130-160 \mathrm{~Hz}, 100$ microsecond pulse width, up to $15 \mathrm{~mA}$ ) was applied to identify the absence of side effects including responses of the internal capsule and ventrocaudal nucleus. After carefully checking for symptomatic fluctuations and side effects, we created a permanent lesion by thermal coagulation $\left(70^{\circ} \mathrm{C}\right.$ for 30 seconds). The electrode was then withdrawn in 2- and 4-mm increments to increase the lesion size, producing 3 contiguous lesions. Similarly, 3 contiguous lesions were made in the vo anterior $(3 \mathrm{~mm}$ anterior to the tentative target) and the vo posterior ( $3 \mathrm{~mm}$ posterior to the tentative target). The accuracy of the coagulated lesions on the vo nucleus of the thalamus and the absence or presence of hemorrhagic complications was confirmed by MRI immediately after the surgery (figure 1B).

\section{Evaluation procedures}

We used the TSFD scale, which is based on Tubiana's musician's dystonia scale, to evaluate each patient's neurologic condition. ${ }^{25,26}$ Scores were based on inability to perform affected tasks (very severe, score of 1 ), perform only easy affected tasks (severe, score of 2 ), perform affected tasks with marked difficulty (moderate, score of 3), nearly normal function (mild, score of 4), and normal functioning (nil, score of 5). We examined TSFD scale scores before surgery; at 1 week, 3 months, and 12 months postoperatively; and at the last available follow-up appointment. We also analyzed postoperative complications and dystonia recurrences. 


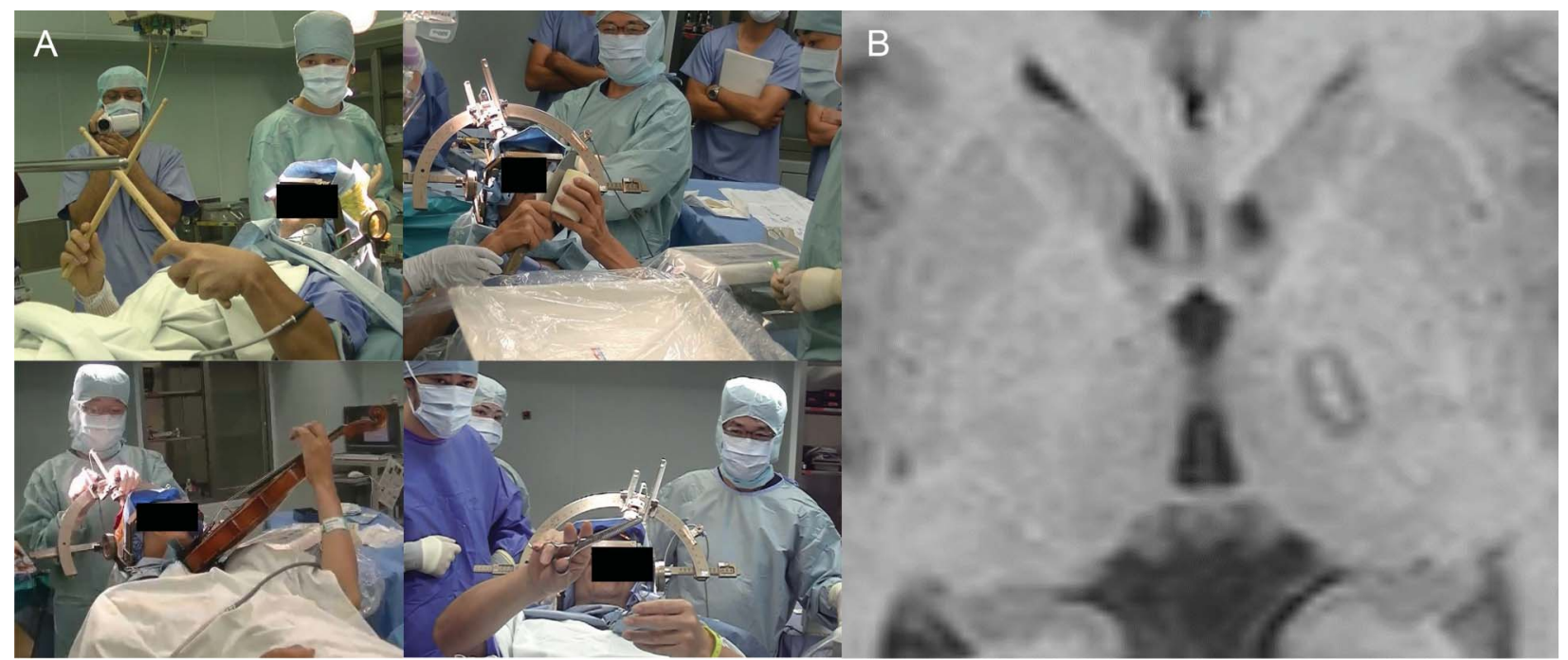

(A) Patients performed affected tasks and were asked to report fluctuations in symptoms. (B) The accuracy of coagulated lesions on the ventro-oral nucleus of the thalamus and hemorrhagic complications were confirmed by MRI immediately after surgery.

Clinical responses were defined as follows: (1) good responders, score $>4$ on TSFD scales at last available follow-up; (2) partial responders, score $<3$ on TSFD scales; and (3) no responders, no change on TSFD scales. Postoperative recurrence was defined as deterioration of TSFD scales after transient improvement. Three-month postoperative MRIs were taken to confirm the lesions within the vo nucleus.

\section{Statistical analysis}

Statistical analysis was performed using the JMP statistical package, version 13.0.0 (SAS Institute, Cary, NC). We examined TSFD scale scores before surgery; at 1 week, 3 months, and 12 months postoperatively; and at the last available follow-up using a 1-way repeated-measures analysis of variance followed by a post hoc Tukey-Kramer adjustment for multiple comparisons. To look for factors that predicted a good surgical response, we used the Spearman correlation coefficient for quantitative variables (age at onset, age at surgery, disease duration, and preoperative TSFD score) and the $\chi^{2}$ test for categorical variables (sex and affected side). All statistical tests were 2 -tailed, and $p<0.05$ was considered to be statistically significant.

\section{Primary research question}

Does vo-thalamotomy safely improve TSFDs and have longterm efficacy?

\section{Classification of evidence}

This study is rated Class IV because of the absence of a nonsurgery group and an open-label design.

\section{Data availability}

Anonymized grouped data will be shared following request from a qualified investigator.

\section{Results}

There were 92 patients with writer's cramp, 58 with musician's dystonia, and 21 with "other" occupational task-related dystonias. The mean clinical follow-up period was $25.4 \pm 32.1$ months (range: 3-165). The mean last available follow-up period was 47.36 months (range: 13-165). Those who presented with musician's dystonias played guitar $(n=26)$, piano $(n=9)$, drums $(n=4)$, bass $(n=2)$, violin $(n=4)$, flute $(n=1)$, clarinet $(n=1)$, saxophone $(n=4)$, koto (Japanese harp; $n=$ 1 ), shamisen (3-stringed Japanese guitar; $n=2$ ), tsuzumi (traditional Japanese hand drum; $\mathrm{n}=1)$, mandolin $(\mathrm{n}=1)$, accordion $(\mathrm{n}=1)$, and banjo $(\mathrm{n}=1)$. Tasks associated with the other occupational dystonias included cooking $(\mathrm{n}=3)$, cutting hair $(n=5)$, carpentry $(n=4)$, sports-related movements $(n=$ $4)$, computer work $(n=4)$, and clock repair $(n=1)$.

The patient characteristics and surgical outcomes are shown in table 1 and figure 2 . The mean age at the time of surgery was $37.1 \pm 12.3$ years (range: $15-63$ ). The mean age at disease onset was $29.1 \pm 11.7$ years (range: $14-57$ ), and the mean disease symptom duration was $8.0 \pm 8.1$ years (range: $1-40$ ). The TSFD scores before vo-thalamotomy and at 1 week $(1.72$ $\pm 0.57,4.33 \pm 0.85[p<0.001]), 3$ months $(4.30 \pm 1.06[p<$ $0.001]), 12$ months $(4.30 \pm 1.13[p<0.001])$, and the last available follow-up after vo-thalamotomy $(4.39 \pm 1.07[p<$ $0.001]$ ) were improved over baseline levels. Other affected daily tasks included writing, keyboard use, chopsticks use, and other tasks in 80 patients (44.9\%). Progression to the contralateral hand (bilateral hand symptoms) was observed in 25 patients $(24.2 \%)$. There were 138 good responder (80.2\%), 30 partial responder (17.5\%), and 4 nonresponder $(2.3 \%)$ patients. Eighteen patients (10.5\%) experienced symptom recurrence after the vo-thalamotomy. No baseline factors (age at 
Table 1 Baseline demographic and clinical characteristics

\begin{tabular}{ll}
\hline \multicolumn{2}{l}{ Constitution of task-specific focal hand dystonia } \\
\hline Writer's cramp & 92 \\
\hline Musician's dystonia & 58 \\
\hline Other occupational dystonia & 21 \\
\hline Total & 171 \\
\hline Sex, M/F & $130 / 41$ \\
\hline Age at onset, $\mathbf{y}$ & $29.2(11.7)[7-57]$ \\
\hline Disease duration, $\mathbf{y}$ & $7.9(8.0)[1-40]$ \\
\hline Age at surgery, $\mathbf{y}$ & $37.1(12.3)[17-67]$ \\
\hline Progression to contralateral side & $25(14.6)$ \\
\hline Progression to other tasks & $80(46.8)$ \\
\hline
\end{tabular}

Data are mean (SD) [range], or number of patients (\%).

surgery, age at onset, disease duration, preoperative TSFD score, sex, and affected side) were significant predictors of surgical response at the last available final follow-up. Thirty patients reported their unemployment caused by TSFDs preoperatively. Postoperatively, 18 patients resumed their work, 4 remained unemployed, and 9 patients were lost to the study.

\section{Adverse events}

Detailed information of adverse events is shown in table 2 . Permanent adverse events developed in 6 patients (3.5\%). These included mild foot weakness $(n=2)$ that did not interfere with patients' daily activities. Temporary adverse events developed in 28 patients (16.4\%). No symptomatic cerebral hemorrhages were observed. Surgical site infection was observed in 2 patients, and another 2 patients developed postoperative chronic subdural hemorrhage. There were no severe neurologic complications.

\section{Recurrence}

Eighteen patients developed recurrent dystonic symptoms after vo-thalamotomy. Of these, 9 patients underwent repeat vo-thalamotomy and 7 patients achieved improvement. Two patients did not exhibit symptomatic improvement. One patient experienced slight improvement after the second thalamotomy and finally achieved dramatic improvement by pallidotomy. Recurrence developed within 1 month in 9 patients and at 3 months in 10 patients.

\section{Discussion}

TSFD can develop following prolonged repetition of various kinds of tasks, mainly occupational tasks. The prognosis for patients with occupational TSFD is poor because it can interfere with occupational tasks despite the availability of conservative treatments. Surgical treatment for TSFD is underexamined because of the lack of large cohort and high-quality studies. This noncontrolled and nonblinded study examined 171 patients who underwent unilateral vo-thalamotomy, most of whom exhibited long-term improvement. The response rate (good and partial responder) was high (97.7\%), and there were only 6 permanent surgery-related complications (3.5\%), which did not interfere with the patients' daily activities. This study supports the safety and long-term efficacy of vo-thalamotomy for TSFD.

BTX injection is a commonly used treatment for patients with TSFD, and its efficacy was demonstrated during several well-

Figure 2 Mean $( \pm S D)$ scores for the TSFD scale before and after surgery

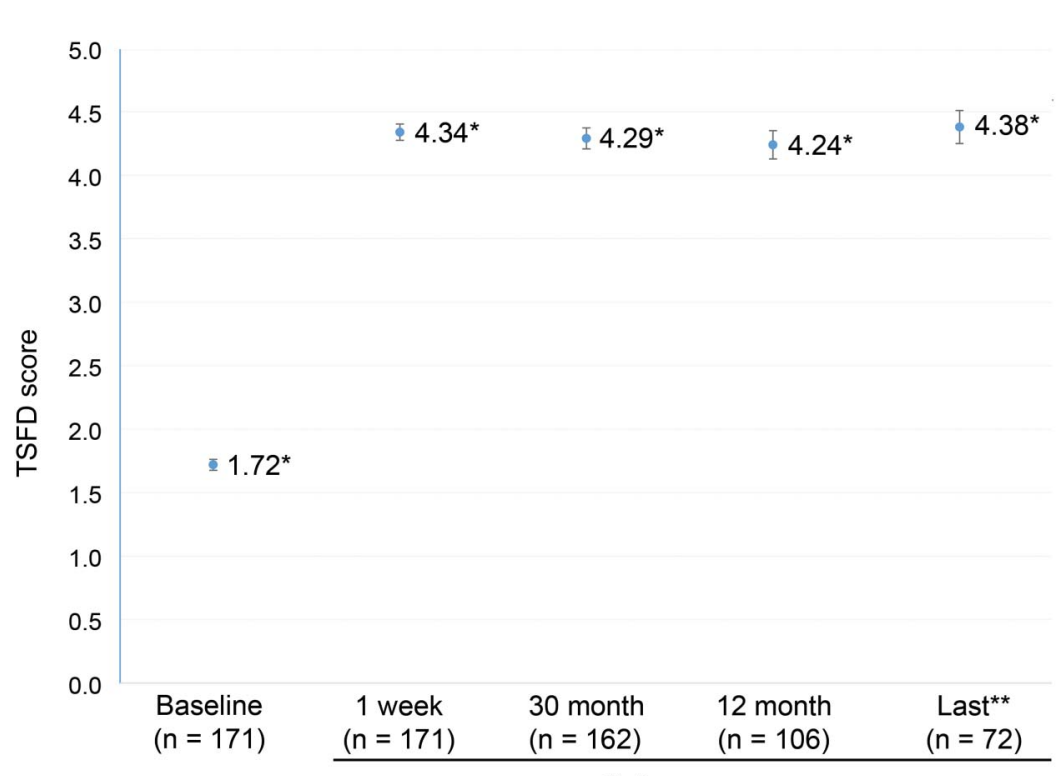

Follow-up
${ }^{*} p<0.001$ for the comparison with the baseline score. **The mean last available follow-up period was 47.36 months (range: 13-165). TSFD = task-specific focal hand dystonia. 
Table 2 Detailed information of adverse events

\begin{tabular}{ll}
\hline Permanent adverse events & \\
\hline Dysarthria & 2 \\
\hline Weakness (foot) & 2 \\
\hline Dysesthesia (hand) & 1 \\
\hline Verbal recall disturbance & $6(3.5)$ \\
\hline Total events & 10 \\
\hline Temporary adverse events & 8 \\
\hline Dysarthria & 6 \\
\hline Verbal recall disturbance & 3 \\
\hline Weakness (hemibody) & 2 \\
\hline Weakness (foot) & $28(16.4)$ \\
\hline Facial palsy & $2(1.2)$ \\
\hline Total events & \\
\hline Other adverse events & \\
\hline Surgical site infection & \\
\hline Chronic subdural hemorrhage & \\
\hline Data are n (\%). & \\
\hline
\end{tabular}

designed studies. Anywhere from $49 \%$ to $69 \%$ of patients with musician's dystonia received significant benefit from BTX. ${ }^{12,27,28}$ However, several articles emphasized that the effectiveness of BTX is limited for TSFD.,29,30 Long-term benefits were observed in only $36 \%$ of patients. ${ }^{27}$ Furthermore, BTX injections have complications, such as muscle weakness, tolerance, and BTX antibodies induced by repetitive injections. Among the patients who stopped BTX therapy, the most common reason was insufficient benefit, ${ }^{31}$ meaning the BTX failed to meet patients' expectations or needs. BTX response rates differ between individuals because of injection technique, accurate targeting of the relevant muscles, and avoidance of toxin spread to adjacent unrelated muscles. Focal hand dystonia has a lower overall response rate, with about $50 \%$ of patients receiving at least a mild benefit, compared with $80 \%$ for cervical dystonia and more than $90 \%$ for blepharospasm. ${ }^{32,33}$ In patients with TSFD, muscle weakness to counteract the spasms is necessary only when performing affected tasks. In other words, continuous weakness resulting from BTX can interfere with all motoric tasks, above and beyond just the affected tasks. And BTX can even hamper the speed and coordination of affected tasks. In patients with TSFD, especially those with musician's dystonia, the need to maintain finely skilled motor control is crucial. There exists a delicate balance between improving dystonic symptoms without exacerbating concurrent residual weakness, resulting in loss of motor function. ${ }^{2}$ Because of the high level of fine motor skills required for continued professional performance, more than half of patients affected with TSFD end their professional careers. ${ }^{10}$ These therapeutic limitations associated with BTX for TSFD are explained by the fact that BTX treatments do not focus on the central neurologic abnormality that causes TSFD. Consequently, pathophysiologybased treatments for TSFD are eagerly anticipated.

The effect of vo-thalamotomy for TSFD was previously reported in several articles. Siegfried et al. ${ }^{23}$ firstly reported vo-thalamotomy for TSFD (writer's cramp) in 1969, finding dramatic improvement. Subsequently, several articles have shown the efficacy of vo-thalamotomy for TSFD in musicians, hairdressers, watchmakers, and table tennis players. ${ }^{7,9,15,19}$ The vo nucleus of the thalamus is a relay point in the corticobasal ganglia-thalamo-cortical circuit and a major termination site for basal ganglia outputs that control the motor cortex. Circuit abnormalities could induce impaired regulation between desired and unwanted movements, ultimately leading to dystonic movements. ${ }^{34}$ Zhuang et al. ${ }^{35}$ reported abnormal neuronal activity recorded in the posterior vo during dystonic movements. Lesioning of the posterior vo immediately decreased dystonia symptoms in patients with abnormal posterior vo neuronal activity. ${ }^{36}$ The effect of vothalamotomy for TSFD may be based on altering the basal ganglia-thalamo-cortical circuit.

Surgical treatments for dystonia have mostly focused on generalized, segmental, or cervical dystonia, which mainly use deep brain stimulation (DBS) directed toward the internal segment of the globus pallidus bilaterally. ${ }^{37,38}$ However, there has been little attention given to treatment of TSFD, even though a great number of patients with refractory TSFD exist, despite the availability of conservative treatments. Only 4 studies report on DBS, ${ }^{14,39-41}$ and the remaining studies used thalamotomy and pallidotomy. DBS has effects almost equaling those of thalamotomy, which are achieved by electrical stimulation on the target nucleus, and does not produce irreversible lesions. The advantages of DBS over thalamotomy are the fact that DBS is a reversible procedure and generally considered safe to use for treating bilateral dystonic symptoms. Although only 2 cases with bilateral musician's hand dystonia have been reported without severe complications, ${ }^{17}$ bilateral thalamotomy continues to carry risks of possible severe pseudobulbar paralysis including dysphagia, dysarthria, and dysphonia. ${ }^{42}$ DBS can provide substantial symptomatic relief without these complications; consequently, DBS is the preferred procedure for bilateral dystonic involvement such as generalized, segmental, and cervical dystonias that generally require bilateral treatment. However, TSFD mostly develops unilaterally (25/171, 14.6\% bilateral symptoms in this study), so most patients do not require bilateral procedures. In the present study of 171 cases, there were only 6 permanent adverse events (3.5\%), and there was no mortality. The rate of symptomatic hemorrhage in this study was quite low (0\%), which is in line with previous reports that revealed a bleeding risk associated with lesioning procedures of $0 \%$ to $2.9 \%{ }^{43-47}$ Unilateral thalamotomy is a feasible and safe procedure. Moreover, TSFD mostly develops at mid-30s. Young-onset diseases require 
long-term management (more than several decades). In the case of DBS, battery replacement adjustment of stimulation parameters is necessary for effective treatment. Furthermore, DBS carries a risk of hardware-related complications such as infections, battery malfunctions, lead migration, and fracture. In a recent systematic review of hardware-related DBS complications in 8,983 patients, the overall risk of hardware-related complications was $11.75 \%$, which is not uncommon. ${ }^{48} \mathrm{Im}$ plantation of mechanical devices into the patient's body can also carry psychological and physiologic burden, especially in young patients. Patients with young-onset TSFD have to continue to be exposed to these risks if DBS is used. Thalamotomy can avoid not only hardware-related complications but also other DBS-related disadvantages. Although DBS is cost-prohibitive in many developing countries, thalamotomy is a more cost-effective option given that DBS can improve TSFD symptoms with a single procedure and does not require postoperative management. Therefore, thalamotomy is a viable option for patients who are not willing to accept hardware implantations, who are unable to visit hospitals that specialize in DBS management, or who are unable to afford DBS.

In this study, 18 patients experienced recurrence of symptoms following transient improvement. As we previously reported, recurrence occurs due to insufficient or incorrect coagulation over the entire vo nucleus of the thalamus. ${ }^{9}$ Until edema surrounding thermocoagulation, which covers the entire vo nucleus, disappears, symptomatic improvement may persist. Heat-related edema in the brain usually disappears within 5 months ${ }^{49}$; this study demonstrated that all recurrence developed within 3 months. In recurrent cases, re-thalamotomy should be appropriately considered before implementation. In this study, 9 of 18 patients with recurrent symptoms underwent re-thalamotomy, which ultimately produced a successful outcome in 7 patients.

Vo-thalamotomy using the Gamma Knife, which does not require craniotomy, is a minimally invasive treatment for TSFD (musician's dystonia). ${ }^{16}$ MRI-guided focused ultrasound thalamotomy, which can also make intracranial focal lesioning without incision, to the ventral intermediate thalamic nucleus has been reported as an effective procedure for various kinds of tremors. ${ }^{50}$ MRI-guided focused ultrasound thalamotomy produces lesions using thermal ablation, and has long-term improvement and safety comparable with radiofrequency thalamotomy. The present study supports the idea that vo-thalamotomy using focused ultrasound is an effective and less invasive treatment for TSFD.

TSFD can develop as a consequence of performing repeated occupational tasks, potentially depriving patients of their livelihoods while diminishing quality of life. We should not ignore the existence of the many patients with TSFD who are refractory to available conservative treatments including BTX, oral medications, and physical therapy. Although further wellpowered studies (prospective, randomized, and double blind) are needed to clarify the safety and efficacy of vo-thalamotomy for TSFD, this study supports our hypothesis that vothalamotomy is a feasible and effective treatment for patients with refractory TSFD.

\section{Author contributions}

S. Horisawa: conception and development of the study design, acquisition and analysis of data, drafting of a significant portion of the manuscript, figures, and tables. T. Ochiai: acquisition of data. S. Goto: acquisition of data. T. Nakajima: acquisition of data. N. Takeda: acquisition of data. T. Hanada: acquisition of data. A. Fukui: acquisition and analysis of data. T. Kawamata: development of the study design. T. Taira: conception and development of the study design, acquisition and analysis of data.

\section{Study funding}

No targeted funding reported.

\section{Disclosure}

S. Horisawa received consulting fees from Boston Scientific. T. Ochiai, S. Goto, T. Nakajima, N. Takeda, A. Fukui, T. Hanada, and T. Kawamata report no disclosures relevant to the manuscript. T. Taira received consulting fees from St. Jude Medical Japan and speaking fees from Daiichi-Sankyo. Go to Neurology.org/ $\mathrm{N}$ for full disclosures.

\section{Publication history}

Received by Neurology June 18, 2018. Accepted in final form September 20, 2018

\section{References}

1. Fahn S, Bressman SB, Marsden CD. Classification of dystonia. Adv Neurol 1998;78: $1-10$.

2. Stahl CM, Frucht SJ. Focal task specific dystonia: a review and update. J Neurol 2017; 264:1536-1541.

3. Sheehy MP, Rothwell JC, Marsden CD. Writer's cramp. Adv Neurol 1988;50:457-472.

4. Le Floch A, Vidailhet M, Flamand-Rouviere C, et al. Table tennis dystonia. Mov Disord 2010;25:394-397.

5. Sitburana O, Ondo WG. Task-specific focal hand dystonia in a professional pistolshooter. Clin Neurol Neurosurg 2008;110:423-424.

6. Adler $\mathrm{CH}$, Crews D, Kahol K, et al. Are the yips a task-specific dystonia or "golfer's cramp"? Mov Disord 2011;26:1993-1996.

7. Horisawa S, Takeda N, Taira T. Watchmaker's dystonia. Mov Disord 2016;3:102-103.

8. Ramirez Gomez CC, Conti E, Montilla Uzcategui V, Aldinio V, Micheli F. Task specific dystonia in a juggler. Parkinsonism Relat Disord 2016;31:151-152.

9. Horisawa S, Goto S, Nakajima T, Ochiai T, Kawamata T, Taira T. Stereotactic thalamotomy for hairdresser's dystonia: a case series. Stereotact Funct Neurosurg 2016;94:201-206.

10. Schuele S, Lederman RJ. Long-term outcome of focal dystonia in string instrumentalists. Mov Disord 2004;19:43-48.

11. Lungu C, Ahmad OF. Update on the use of botulinum toxin therapy for focal and taskspecific dystonias. Semin Neurol 2016;36:41-46.

12. van Vugt FT, Boullet L, Jabusch HC, Altenmuller E. Musician's dystonia in pianists: long-term evaluation of retraining and other therapies. Parkinsonism Relat Disord 2014;20:8-12

13. Balash Y, Giladi N. Efficacy of pharmacological treatment of dystonia: evidence-based review including meta-analysis of the effect of botulinum toxin and other cure options. Eur J Neurol 2004;11:361-370.

14. Doshi PK, Ramdasi RV, Karkera B, Kadlas DB. Surgical interventions for task-specific dystonia (writer's dystonia). Ann Indian Acad Neurol 2017;20:324-327.

15. Asahi T, Taira T, Ikeda K, Yamamoto J, Sato S. Improvement of table tennis dystonia by stereotactic ventro-oral thalamotomy: a case report. World Neurosurg 2017;99: 810.e1-810.e4.

16. Horisawa S, Tamura N, Hayashi M, et al. Gamma Knife ventro-oral thalamotomy for musician's dystonia. Mov Disord 2017;32:89-90.

17. Horisawa S, Goto S, Nakajima T, Kawamata T, Taira T. Bilateral stereotactic thalamotomy for bilateral musician's hand dystonia. World Neurosurg 2016;92:585.e21-585.e25

18. Asahi T, Koh M, Kashiwazaki D, Kuroda S. Stereotactic neurosurgery for writer's cramp: report of two cases with an overview of the literature. Stereotact Funct Neurosurg 2014;92:405-411. 
19. Horisawa S, Taira T, Goto S, Ochiai T, Nakajima T. Long-term improvement of musician's dystonia after stereotactic ventro-oral thalamotomy. Ann Neurol 2013;74: 648-654.

20. Shibata T, Hirashima Y, Ikeda H, Asahi T, Hayashi N, Endo S. Stereotactic Voa-Vop complex thalamotomy for writer's cramp. Eur Neurol 2005;53:38-39.

21. Taira T, Hori T. Stereotactic ventrooralis thalamotomy for task-specific focal hand dystonia (writer's cramp). Stereotact Funct Neurosurg 2003;80:88-91.

22. Goto S, Tsuiki H, Soyama N, et al. Stereotactic selective Vo-complex thalamotomy in a patient with dystonic writer's cramp. Neurology 1997;49:1173-1174.

23. Siegfried J, Crowell R, Perret E. Cure of tremulous writer's cramp by stereotaxic thalamotomy: case report. J Neurosurg 1969;30:182-185.

24. Schaltenbrand G, Wahren W. Atlas for Stereotaxy of the Human Brain: Architectonic Organisation of the Thalamic Nuclei by Rolf Hassler. Stuttgart: Thieme; 1977.

25. Tubiana R. Musician's focal dystonia. Hand Clin 2003;19:303-308, vii.

26. Peterson DA, Berque P, Jabusch HC, Altenmüller E, Frucht SJ. Rating scales for musician's dystonia: the state of the art. Neurology 2013;81:589-598.

27. Schuele S, Jabusch HC, Lederman RJ, Altenmüller E. Botulinum toxin injections in the treatment of musician's dystonia. Neurology 2005;64:341-343.

28. Jabusch HC, Zschucke D, Schmidt A, Schuele S, Altenmuller E. Focal dystonia in musicians: treatment strategies and long-term outcome in 144 patients. Mov Disord 2005;20:1623-1626.

29. Karp BI. Botulinum toxin treatment of occupational and focal hand dystonia. Mov Disord 2004;19(suppl 8):S116-S119.

30. Sadnicka A, Kassavetis P, Parees I, Meppelink AM, Butler K, Edwards M. Task-specific dystonia: pathophysiology and management. J Neurol Neurosurg Psychiatry 2016;87. 968-974.

31. Lungu C, Karp BI, Alter K, Zolbrod R, Hallett M. Long-term follow-up of botulinum toxin therapy for focal hand dystonia: outcome at 10 years or more. Mov Disord 2011; 26:750-753.

32. Hallett M, Benecke R, Blitzer A, Comella CL. Treatment of focal dystonias with botulinum neurotoxin. Toxicon 2009;54:628-633.

33. Jankovic J. Botulinum toxin therapy for cervical dystonia. Neurotox Res 2006;9: $145-148$.

34. Sohn YH, Hallett M. Disturbed surround inhibition in focal hand dystonia. Ann Neurol 2004;56:595-599.

35. Zhuang P, Li Y, Hallett M. Neuronal activity in the basal ganglia and thalamus in patients with dystonia. Clin Neurophysiol 2004;115:2542-2557.
36. Lenz FA, Jaeger CJ, Seike MS, et al. Thalamic single neuron activity in patients with dystonia: dystonia-related activity and somatic sensory reorganization. J Neurophysiol 1999;82:2372-2392.

37. Kiss ZH, Doig-Beyaert K, Eliasziw M, Tsui J, Haffenden A, Suchowersky O. The Canadian multicentre study of deep brain stimulation for cervical dystonia. Brain 2007; 130:2879-2886.

38. Kupsch A, Benecke R, Muller J, et al. Pallidal deep-brain stimulation in primary generalized or segmental dystonia. New Engl J Med 2006;355:1978-1990.

39. Cho CB, Park HK, Lee KJ, Rha HK. Thalamic deep brain stimulation for writer's cramp. J Korean Neurosurg Soc 2009;46:52-55.

40. Fukaya C, Katayama Y, Kano T, et al. Thalamic deep brain stimulation for writer's cramp. J Neurosurg 2007;107:977-982.

41. Goto S, Shimazu H, Matsuzaki K, et al. Thalamic Vo-complex vs pallidal deep brain stimulation for focal hand dystonia. Neurology 2008;70:1500-1501.

42. Tasker RR, Doorly T, Yamashiro K. Thalamotomy in generalized dystonia. Adv Neurol 1988;50:615-631.

43. Vitek JL, Bakay RA, Hashimoto T, et al. Microelectrode-guided pallidotomy: technical approach and its application in medically intractable Parkinson's disease. J Neurosurg 1998;88:1027-1043.

44. Blomstedt P, Hariz MI. Are complications less common in deep brain stimulation than in ablative procedures for movement disorders? Stereotact Funct Neurosurg 2006;84:72-81.

45. Alterman RL, Sterio D, Beric A, Kelly PJ. Microelectrode recording during posteroventral pallidotomy: impact on target selection and complications. Neurosurgery 1999;44:315-323.

46. Tasker RR, Munz M, Junn F, et al. Deep brain stimulation and thalamotomy for tremor compared. Acta Neurochir Suppl 1997;68:49-53.

47. Linhares MN, Tasker RR. Microelectrode-guided thalamotomy for Parkinson's disease. Neurosurgery 2000;46:390-395; discussion 395-398.

48. Jitkritsadakul O, Bhidayasiri R, Kalia SK, Hodaie M, Lozano AM, Fasano A. Systematic review of hardware-related complications of deep brain stimulation: do new indications pose an increased risk? Brain Stimul 2017;10:967-976.

49. Tomlinson FH, Jack CR Jr, Kelly PJ. Sequential magnetic resonance imaging following stereotactic radiofrequency ventralis lateralis thalamotomy. J Neurosurg 1991 74:579-584.

50. Elias WJ, Lipsman N, Ondo WG, et al. A randomized trial of focused ultrasound thalamotomy for essential tremor. N Engl J Med 2016;375:730-739. 


\section{Neurology}

\section{Safety and long-term efficacy of ventro-oral thalamotomy for focal hand dystonia: A retrospective study of 171 patients \\ Shiro Horisawa, Taku Ochiai, Shinichi Goto, et al.}

Neurology 2019;92;e371-e377 Published Online before print December 26, 2018

DOI 10.1212/WNL.0000000000006818

\section{This information is current as of December 26, 2018}

\section{Updated Information \&} Services

References

Subspecialty Collections

Permissions \& Licensing

Reprints including high resolution figures, can be found at: http://n.neurology.org/content/92/4/e371.full

This article cites 49 articles, 5 of which you can access for free at: http://n.neurology.org/content/92/4/e371.full\#ref-list-1

This article, along with others on similar topics, appears in the following collection(s):

\section{Dystonia}

http://n.neurology.org/cgi/collection/dystonia

Surgery/Stimulation

http://n.neurology.org/cgi/collection/surgery-stimulation

Information about reproducing this article in parts (figures,tables) or in its entirety can be found online at:

http://www.neurology.org/about/about_the_journal\#permissions

Information about ordering reprints can be found online:

http://n.neurology.org/subscribers/advertise

Neurology ${ }^{\circledR}$ is the official journal of the American Academy of Neurology. Published continuously since 1951, it is now a weekly with 48 issues per year. Copyright Copyright ( 2018 The Author(s). Published by Wolters Kluwer Health, Inc. on behalf of the American Academy of Neurology.. All rights reserved. Print ISSN: 0028-3878. Online ISSN: 1526-632X.

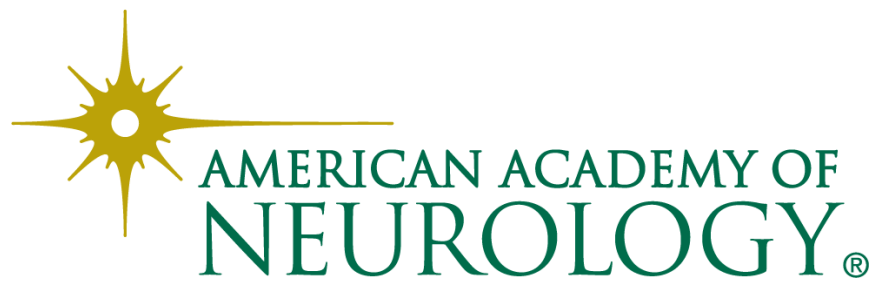

